\title{
More evidence of the effects of voting technology on election outcomes
}

\author{
Maarten A. Allers • Peter Kooreman
}

Received: 6 June 2008 / Accepted: 13 November 2008 / Published online: 22 November 2008

(C) The Author(s) 2008. This article is published with open access at Springerlink.com

\begin{abstract}
Using two different data sources-municipal level data and individual data-we consider several hitherto unexplored aspects of the relationship between voting technology and election outcomes. We distinguish between introductory and permanent effects of electronic voting, and between national and municipal elections. We test for a possible asymmetry between the effect of moving from paper ballots to electronic voting, and vice versa, and we control for polling station density. We find a positive but temporary effect of electronic voting on voter turnout, a negative effect on the fraction of residual votes, and no effect on the share of left wing parties.
\end{abstract}

Keywords Voting technology $\cdot$ Elections $\cdot$ Turnout $\cdot$ Residual votes

\section{JEL Classification D72}

\section{Introduction}

After having served democracies for decades, the paper ballot is being replaced by technologically more advanced ways of casting a vote in many countries. But the trend toward voting by touching a screen, pushing a button, or clicking a mouse is not uncontroversial. Problems associated with voting technology have been reported for Belgium, Brazil, Estonia, France, Germany, India, Ireland, the Netherlands, United Kingdom, United States, Switzerland, and other countries. ${ }^{1}$ While vulnerability to fraud is a central concern, elec-

\footnotetext{
${ }^{1}$ See, e.g., for the United States, New York Times. 2007. "Florida Acts to Eliminate Touch-Screen Voting System" and "Trust in Paper." (Editorial), May 5. For Germany see Kurz et al. (2007) and for Ireland Commission on Electronic Voting (2004).

M.A. Allers (凶)

Center for Research on Local Government Economics (COELO), University of Groningen, P.O. Box 800, 9700AV, Groningen, The Netherlands

e-mail: m.a.allers@rug.nl

P. Kooreman

Department of Economics, Tilburg University, Tilburg, The Netherlands
} 
tronic voting has also been criticized for not sufficiently protecting the legal right to cast a vote confidentially. Shortly before the Dutch parliamentary elections in November 2006, it was found that votes cast with electronic voting machines of a specific make could be traced from a distance with specialized equipment. ${ }^{2}$ As a response, a number of municipalities, including Amsterdam, reverted to paper ballots for casting votes. In 2007, the Dutch government outlawed the use of all existing voting machines.

These events stress the need for insight into the possible effects of voting technologies on election outcomes. Although quite a few studies have been carried out in this field, most of these rely on cross-sectional analysis (e.g., Brady et al. 2001; Herron and Wand 2007; Kimball et al. 2004; Knack and Kropf 2003; Tomz and Van Houweling 2003). However, as shown by Ansolabehere and Stewart (2005), cross-sectional analyses appear to be seriously misspecified. Ansolabehere and Stewart (2005) use a fixed effects panel data analysis to study the effect of voting technology on the proportion of residual (uncounted) votes in presidential, gubernatorial, and senatorial elections the United States. They conclude that existing voting technologies differ significantly in their performance with respect to residual votes. Ansolabehere and Stuart show that most of the variation in the residual vote is attributable to unobservable county characteristics. Therefore, they stress that cross-sectional analysis is not appropriate to study the effects of voting equipment.

Lott (2008) studies non-voted ballots using panel data from Ohio covering the presidential elections in 1992, 1996, and 2000. He concludes that different voting technologies give rise to different degrees of "voter fatigue". While non-voting increases with all technologies as voters move down the ballot to races that are deemed to be less important, this increase varies systematically with the type of voting system used. Lott stresses that systems that produce fewer non-votes in presidential elections may produce more non-votes for other offices.

Apart from having an impact on residual votes, voting technology might also influence voter turnout and election results. Card and Moretti (2007) analyze the effects of touchscreen voting using data on the 2000 and 2004 US presidential elections. They conclude that this has had a negative effect on voter turnout, and a small but statistically significant positive effect on electoral support for George Bush. Because the effect was not larger in swing states, or in states with a Republican Secretary of State, the authors conclude that it was probably not the result of irregularities or fraud. Card and Moretti do not make a distinction between temporary and permanent effects of a change in voting technology. It is conceivable that a switch to a new technology temporarily affects election outcomes, without having a permanent effect.

Apart from an effect on the residual vote rate, voter turnout and election results, voting technology may influence the number of mistakenly cast votes. Dee (2007) presents evidence that punch-card systems significantly increased the frequency of this kind of error in the 2003 Californian gubernatorial recall election.

Instead of looking at actual elections, Herrnson et al. (2008) rely on expert reviews of voting systems and on laboratory experiments to analyze the effects of voting technology. They conclude that some combinations of voting systems, ballot formats and voting tasks lead to more errors than others. E.g., when citizens can vote for more than one candidate for some offices, paper ballots, optical scan systems and standard touch screen systems are more accurate than systems that present the entire ballots at one time.

\footnotetext{
${ }^{2}$ The website of a Dutch pressure group against electronic voting contains links to various reports and video clips highlighting such problems, some of which are available in English. See http://www. wijvertrouwenstemcomputersniet.nl/English.
} 
The present paper supplements previous studies of the effect of voting technology on residual votes, voter turnout and election results in a number of ways. First, by considering a sequence of nine different Dutch elections during the period 1994-2006, we can distinguish between the impact of the introduction of electronic voting and its more permanent impact. Since the introduction of electronic voting usually goes along with informational campaigns and extra media attention, these two effects are likely to be different.

Second, we distinguish between national and municipal elections. The distinction is of interest since in a system of proportional representation (as in the Netherlands), incentives for fraud are potentially larger in municipal elections than in elections for the national Parliament. This is because it takes fewer votes to change election outcomes at the local level. Thus, if we find that the effect of electronic voting is larger in municipal elections than in national elections, this might be interpreted as an indication of irregularities.

Third, while previous empirical results typically rely on one-time changes from paper ballots to electronic voting, our data also include a number of reverse changes as a result of the November 2006 events. This allows us to consider possible asymmetries between the effect of moving from paper ballots to electronic voting and vice versa.

Fourth, as voting machines are expensive, their introduction may go along with a reduction in the number of polling stations. Since this increases individuals' average distance to a polling station-and hence costs of voting - polling station density is crucial to control for in establishing the causal impact of electronic voting on elections outcomes, in particular voter turnout. Previous studies ignore this.

Finally, while previous work seems to be focused entirely on the United States, we present evidence from the Netherlands. Using two different data sources-municipal level data on actual voting behavior and a panel survey among eligible voters-we estimate the effects of voting technology on voter turnout, election results (the share of left wing parties), and the residual vote rate. We find a small positive but temporary effect of electronic voting on voter turnout, and a strong negative effect on the share of residual votes. We do not find an effect on the share of left wing parties, either in municipal, or in national elections.

This paper is organized as follows. Section 2 describes voting technology in the Netherlands and the municipal level data we use. The empirical analysis of the municipal level data is discussed in Section 3, and Section 4 presents the results. The robustness check based on individual-level data is presented in Section 5. Section 6 concludes.

\section{Voting technology in the Netherlands and municipal level data}

The Netherlands (16 million inhabitants) has three territorial levels of government: the national government, 12 provinces and (in 2006) 458 municipalities. Each level has its own government, and a parliament (or council) which is elected by a system of proportional representation. With very few exceptions, governments are formed by a coalition of political parties. All Dutch nationals aged 18 or more are entitled to vote, except those expressly excluded (e.g., the mentally ill). Citizens of other countries of the European Union residing in the Netherlands can vote in municipal elections, as can residents of other countries who have resided legally in the Netherlands for at least five years.

There is only one election at a time, so ballots do not list several races, like, e.g., in the United States. Dutch ballots list the participating political parties (in columns) and the persons running for these parties (in rows). People vote by selecting one of the persons on the ballot. Although there are no more than ten parties that play a significant role in Dutch 
Table 1 Voting in the Netherlands

\begin{tabular}{|c|c|c|c|c|c|c|c|c|c|}
\hline & \multicolumn{4}{|c|}{$\begin{array}{l}\text { Municipal elections } \\
\text { (288 municipalities) }\end{array}$} & \multicolumn{5}{|c|}{$\begin{array}{l}\text { National elections } \\
\text { (319 municipalities) }\end{array}$} \\
\hline & 1994 & 1998 & 2002 & 2006 & 1994 & 1998 & 2002 & 2003 & 2006 \\
\hline Voter turnout (percentage) & 69.4 & 65.2 & 63.5 & 63.2 & 82.0 & 77.0 & 82.2 & 83.1 & 82.9 \\
\hline Percentage left wing votes & 29.5 & 28.0 & 23.8 & 29.8 & 40.3 & 44.5 & 28.9 & 38.0 & 39.4 \\
\hline Percentage residual votes & 0.432 & 0.271 & 0.226 & 1.000 & 0.275 & 0.152 & 0.121 & 0.100 & 0.131 \\
\hline Fraction electronic voting & 0.361 & 0.722 & 0.917 & 0.962 & 0.373 & 0.734 & 0.922 & 0.937 & 0.937 \\
\hline Fraction voting technology change $\mathrm{e}^{\mathrm{a}}$ & 0.188 & 0.354 & 0.184 & 0.017 & 0 & 0 & 0 & 0.016 & 0.031 \\
\hline Fraction reverted to paper ballot & - & - & - & - & - & - & - & - & 0.028 \\
\hline $\begin{array}{l}\text { Number of polling stations per } \\
1000 \text { eligible voters }\end{array}$ & 0.897 & 0.832 & 0.804 & 0.774 & 0.907 & 0.841 & 0.810 & 0.804 & 0.781 \\
\hline $\begin{array}{l}\text { Fraction allowing to vote at polling } \\
\text { station of choice }\end{array}$ & - & - & - & 0.549 & - & - & - & - & 0.621 \\
\hline
\end{tabular}

${ }^{\text {a } F r a c t i o n ~ w h e r e ~ a ~ d i f f e r e n t ~ v o t i n g ~ t e c h n o l o g y ~ w a s ~ u s e d ~ t h a n ~ i n ~ t h e ~ p r e c e d i n g ~ l o c a l, ~ p r o v i n c i a l ~ o r ~ n a t i o n a l ~}$ election. Note that Fraction electronic voting may increase even when Fraction voting technology change is zero, as electronic voting may have been introduced in elections for a different government level

national politics, in some elections, more than 25 parties compete, some of which only exist locally.

Municipalities are responsible for organizing both the municipal and national elections. They decide what voting technology to use, and how many polling stations to set up. In the past two decades, virtually all municipalities replaced paper ballots by direct-record electronic (DRE) voting machines (Table 1). Mechanical voting systems (punch cards, lever machines) have never been used in the Netherlands, except in a small-scale and disastrous experiment in the 1960s. Paper ballots are hand-counted. Two competing Dutch firms provided the electronic voting machines, one of them (Nedap) having by far the largest market share. Election dates are uniform in all municipalities, with the exception of local elections in merging municipalities, which we exclude from our study. Other election regulations are uniform across the country.

We collected data on voting technology by contacting all individual municipalities. For some municipalities we failed to establish exactly when DREs were introduced, as local officials find it more difficult to provide that information the further the moment lies back in history. We therefore decided to focus on the municipal council elections in 1994, 1998, 2002, and 2006, and the national elections (for parliament) in 1994, 1998, 2002, 2003, and 2006. Data on election outcomes and on demographic control variables were obtained from Statistics Netherlands. ${ }^{3}$ Another complication is the ongoing process of municipal mergers. We constructed a panel dataset of all municipalities that existed in the same form during the period 1994-2006. This leaves us with a sample of 319 municipalities that covers about

\footnotetext{
${ }^{3}$ Data on the number of polling stations per municipality before 2006 are from Statistics Netherlands (www.cbs.nl). For 2006, we collected these data ourselves. For the 1994 national elections, the Statistics Netherlands data contain four very unlikely values for residual votes (with a share of residual votes of up to $50 \%$ ). These have been eliminated from the dataset.
} 
two-thirds of eligible voters. ${ }^{4}$ As mentioned, a small number of municipalities reverted to paper and pencil ballots just prior to the November 2006 national elections. See Table 1 for details.

\section{Empirical analysis}

Because DREs were introduced in different elections in different municipalities, we are able to hold constant the many other factors at the municipal level that influence election outcomes. Using the municipal level data on actual voting behavior, we estimate separate models for three types of election outcomes: voter turnout, the share of left wing parties, and residual vote rate. Residual votes are votes cast but not attributed to one of the candidates. A residual vote can be due to an error, or to an intentionally invalid or blank vote. When paper ballots are used, voters can fail to tick one box clearly. When electronic voting equipment is used, it is still possible to cast a blank vote, by pushing the appropriate button. However, errors on behalf of the voter leading to a residual vote are virtually impossible.

We use three types of explanatory variables. First, we include variables describing the voting technology that was used (dummies for electronic voting, and for a change in voting technology). The inclusion of the voting technology change dummy allows us to assess whether the effects of voting technology are temporary or permanent. For example, some people might find new technology confusing and therefore not vote, ${ }^{5}$ but such an effect could disappear as soon as once-new technology has become familiar. By the same token, the introduction of a new way of voting is typically accompanied by extra publicity, as the municipality informs voters how to use the new equipment.

We also include two variables related to the (time) costs of voting. The first is a dummy for whether voters were allowed to vote at the polling station of their own choice rather than at the station in the ward where they reside. This new option, which was introduced in the 2006 municipal elections by about half of the municipalities, allows people, e.g., to vote in the vicinity of their work, or where they shop. The second is the number of polling stations per 1000 eligible voters. We include the latter variable since municipalities appear to substantially reduce the number of polling stations upon introduction of electronic voting machines in order to save costs. A lower number of polling stations not only increases the average travel costs of voting, but may also result in longer lines at the remaining stations. Haspel and Knotts (2005), studying the 2001 Atlanta mayoral race, find that small differences in the distance to the polls may have a significant effect on voter turnout. For the present dataset, the coefficient in a regression of the number of polling stations per 1000 inhabitants on a dummy for electronic voting (controlling for municipal fixed effects and year dummies) is -0.114 ( $t$-value -11.0 ), implying a strong and highly significant reduction in the average number of polling stations by about $11 \%$. Given this strong correlation, failure to control for the number of polling stations is likely to induce a downward bias in the effect of electronic voting. ${ }^{6}$

\footnotetext{
${ }^{4}$ Our sample for municipal elections is smaller (288) for two reasons. First, municipalities that were about to merge in 2007 did not hold local elections in 2006. Second, municipalities that were merged in 1993 did not hold local elections in 1994.

${ }^{5}$ Roseman and Stephenson (2005) find that after a statewide change to DREs, turnout among the elderly was lower than before in Georgia's gubernatorial elections.

${ }^{6}$ There are several reports of precincts not being allocated enough voting machines during the 2004 Presidential election in the United States; see, for example, http://copperas.com/machinery.
} 
Second, we control for time-varying demographic indicators (fraction of women, people aged 18-30, aged 65+, divorced, single, number of inhabitants, and number of inhabitants per square kilometer). Finally, we include municipality specific fixed effects to control for time-invariant unobservable determinants of voting behavior (Hausman tests strongly reject the random effects specification in all cases), and year dummies to filter out nationwide swings in voter sentiment.

We estimate by weighted least squares. We use the number of eligible voters in each municipality in 1998 as weights. Estimating a linear probability model on the basis of aggregate data complicates the calculation and interpretation of standard errors. The error term in the linear probability model at the individual level has variance $p_{i}\left(1-p_{i}\right)$, where $p_{i}$ is individual $i$ 's probability to vote (or another outcome). The error term in the model at the municipality level has variance $\left(1 / n^{2}\right) \sum_{i} p_{i}\left(1-p_{i}\right)$, where $n$ is the number of eligible voters. Thus the appropriate weighting factor would be $n / \sqrt{\sum_{i} p_{i}\left(1-p_{i}\right)}$ rather than $n$, and using $n$ as an approximation introduces heterogeneity in the aggregate error terms. Also, in the present fixed-effects setting, standard errors within municipalities are likely to exhibit autocorrelation (Bertrand et al. 2004). Ignoring this risks perceiving significant effects where none exist. We therefore report $t$-values based on robust standard errors clustered by municipality, which are typically larger than uncorrected standard errors.

\section{Results}

Before we turn to our statistical analysis, we present our municipal level data graphically. This allows us to visualize voting trends, and, more importantly, to show whether there are pre-existing levels or trends that render early and late adopters of DREs incomparable. This is important because, in our setup, identification is based on differences in the timing of the introduction of DREs across municipalities. We compare changes in municipalities that adopt DREs in different elections. In order to do so, municipalities that adopt DREs at different moments must be comparable. ${ }^{7}$

Figure 1 shows voting patters in national elections separately for municipalities that introduced DREs before 1998, for those that adopted DREs in 1998, and for those that introduced DREs after 1998 or not at all. For both voter turnout and the share of left-wing votes, trends are identical, and levels similar. No effect of the use of DREs is apparent from Fig. 1. The same holds true for municipal elections (Fig. 2). As far as turnout and the left wing vote are concerned, municipalities introducing DREs at different times seem to be comparable, and the effect of DREs appears small or non-existent.

This is not the case when we look at residual vote rates, however. In 1994, municipalities that already had introduced electronic voting at the time have a lower share of residual votes than municipalities still using paper ballots. This is true for both municipal and national elections. The reason might be that DREs are characterized by a lower residual vote rate than paper ballots. In 1998, the share of residual votes in municipalities introducing DREs drops to the same low level as found in early adopters. Again, this is true for both municipal and national elections. But here the similarity ends. In the 2002 and 2003 national elections, the residual vote rate decreases in municipalities which had not yet adopted DREs in 1998. The share of residual votes remains higher in this group of 'late adopters', but this is unsurprising, as some of these did not adopt DREs at all (Table 1). In the 2006 national

\footnotetext{
${ }^{7}$ Ideally, we would like to instrument electronic voting (Besley and Case 2000), but suitable instruments are unavailable. The cost of DREs, a potential instrument, does not vary across municipalities.
} 

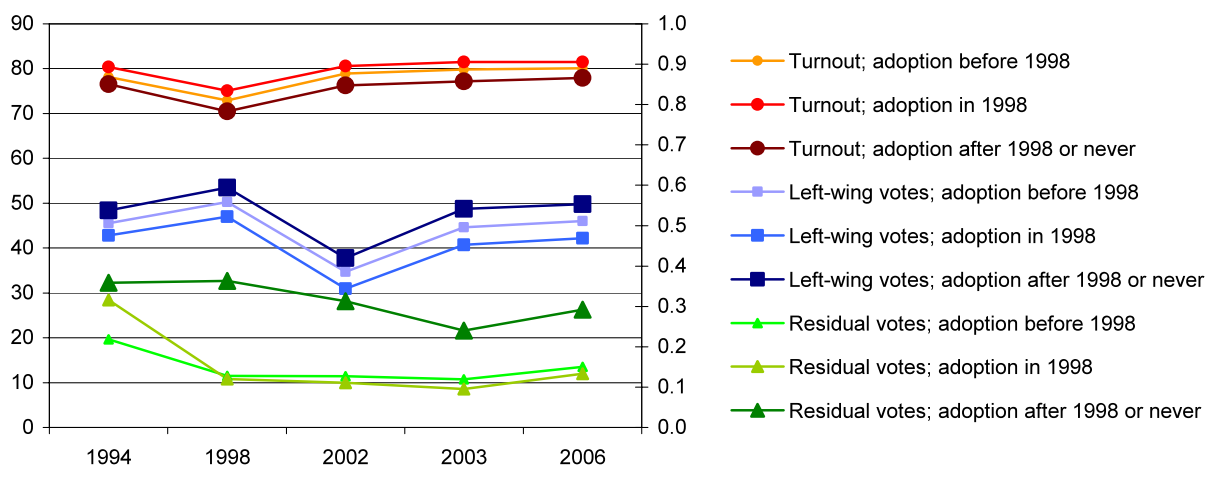

Share of residual votes on right-hand axis

Fig. 1 Voting patterns by year of adoption of DREs; National elections (percentages)
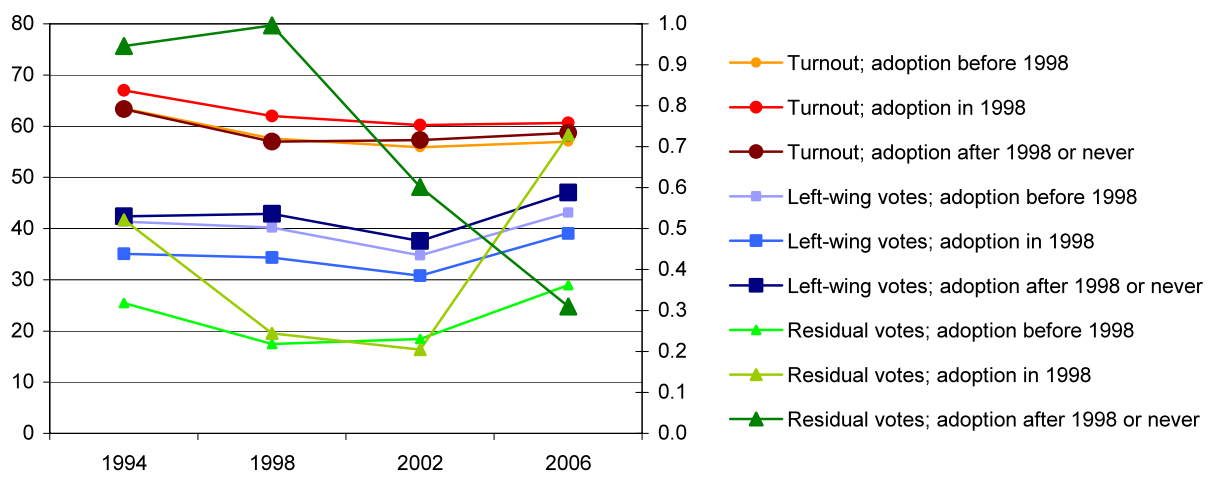

Share of residual votes on right-hand axis

Fig. 2 Voting patterns by year of adoption of DREs; Municipal elections (percentages)

elections, the share of residual votes increases for all categories in a similar way. Together, these national election voting patterns seem to suggest a negative effect of DREs on the residual vote. There are no indications that early and late adopters are not comparable as far as national elections are concerned.

However, from Fig. 2 it is evident that, in municipal elections, localities that had not (yet) adopted DREs in 1998 had high residual vote rates in 1994 compared with municipalities that had used DREs in 1998, but not in 1994. This difference cannot be attributed to voting technology, as both these categories used paper ballots in 1994. In the 2006 municipal elections, the residual vote rate increases sharply in the group that adopted DREs in 1998, while this share remains much lower in the other groups. Thus, municipalities that adopted DREs in different years may not be comparable with respect to residual vote patterns in municipal elections. Blank votes are sometimes used as protest against "politics" in general, especially in municipal elections. Because the extent to which blank votes are cast in municipal elections depends on local circumstances which change from election to election (Brady et al. 2001), an analysis of residual votes is perhaps most fruitful at the national level. Therefore, we will restrict our analysis of municipal elections to turnout and the left wing vote. 
Although figures may be useful to display voting patterns, they cannot tell us whether there is a relationship between voting technology and election outcomes. For that purpose, we need a statistical analysis. The upper panel of Table 2 shows that electronic voting seems to have a positive effect on voter turnout in municipal elections (column 1) and a negative effect in national elections (column 4). After controlling for polling station density, this different effect on local and national elections disappears: the negative effect of electronic voting in national elections becomes insignificant (column 5), while the positive effect in municipal elections gains strength (column 2). Including a dummy for changes in voting technology reveals that only two thirds of the effect of DREs in municipal elections is permanent (column 3). The coefficient of the permanent effect is not statistically significant at the $95 \%$ confidence level. The introductory effect in national elections is positive and significant (column 6), but this is based on only a very small number of first-time electronic voting cases-most municipalities that introduced electronic voting did so in a municipal election; cf. Table 1.8

The omission of the number of polling stations induces a downward bias in the effects coefficient for electronic voting. This was expected, because polling station density has a positive effect on turnout. Thus, municipalities intent on increasing turnout could consider raising the number of polling stations. However, a more cost-effective way to promote turnout is allowing voters to vote at the polling station of their own choice. Table 2 shows that this increases turnout by about one percentage point in both municipal and national elections.

Our result suggests that the significant negative effect of touch-screen voting on turnout, especially for Hispanics, reported by Card and Moretti (2007), might be partly due to not controlling for touch-screen voting machine density. Thus, in addition to the possible interpretations suggested by Card and Moretti (intimidation, distrust, limited English proficiency), lower turnout for Hispanics might be related to higher voting costs and a more limited access to transportation.

Voting technology might also influence the shares of the competing political parties. Conventional wisdom holds that high turnout favors Democrats in the United States and left wing parties in Europe, although this view is contentious (e.g., Nagel and McNulty 1996). It is conceivable that DREs attract or deter groups (e.g., the elderly) that tend to vote for particular parties. We investigate this possibility by looking at the share of left-wing parties; see the middle panel of Table 2. While the coefficients suggest that the left wing share drops when electronic voting machines are used, the effects are statistically insignificant. Including voter turnout in the regression lowers the DRE coefficient even further in municipal elections. There is no significant effect of turnout on the left wing vote, however.

We find that electronic voting does lower the proportion of residual votes; see the lower panel of Table 2. Our result differs from that of Ansolabehere and Stewart (2005), who find that DREs perform comparably to paper in US gubernatorial and senatorial elections, and worse in presidential elections. ${ }^{9}$ Here, we look at national elections only, as municipalities adopting DREs at different moments may not be comparable with respect to the share of residual votes (see above). The negative effect of DREs on residual votes is almost entirely related to electronic voting itself, not its introduction. Electronic voting reduces the residual vote rate by as much as 0.13 percentage points. The inclusion of turnout does not affect the

\footnotetext{
${ }^{8}$ Electronic voting has been introduced in most municipalities in local elections, in some municipalities in national elections and in a few in provincial elections. This explains why "Fraction electronic voting" shown in Table 1 does not increase with "Fraction voting technology change" reported in the same table.

${ }^{9}$ Lott (2008) also finds that non-voting depends on the type of voting system used, but his dataset does not contain paper ballots, so we cannot compare our result to his.
} 
Table 2 Effects of voting technology on election outcomes

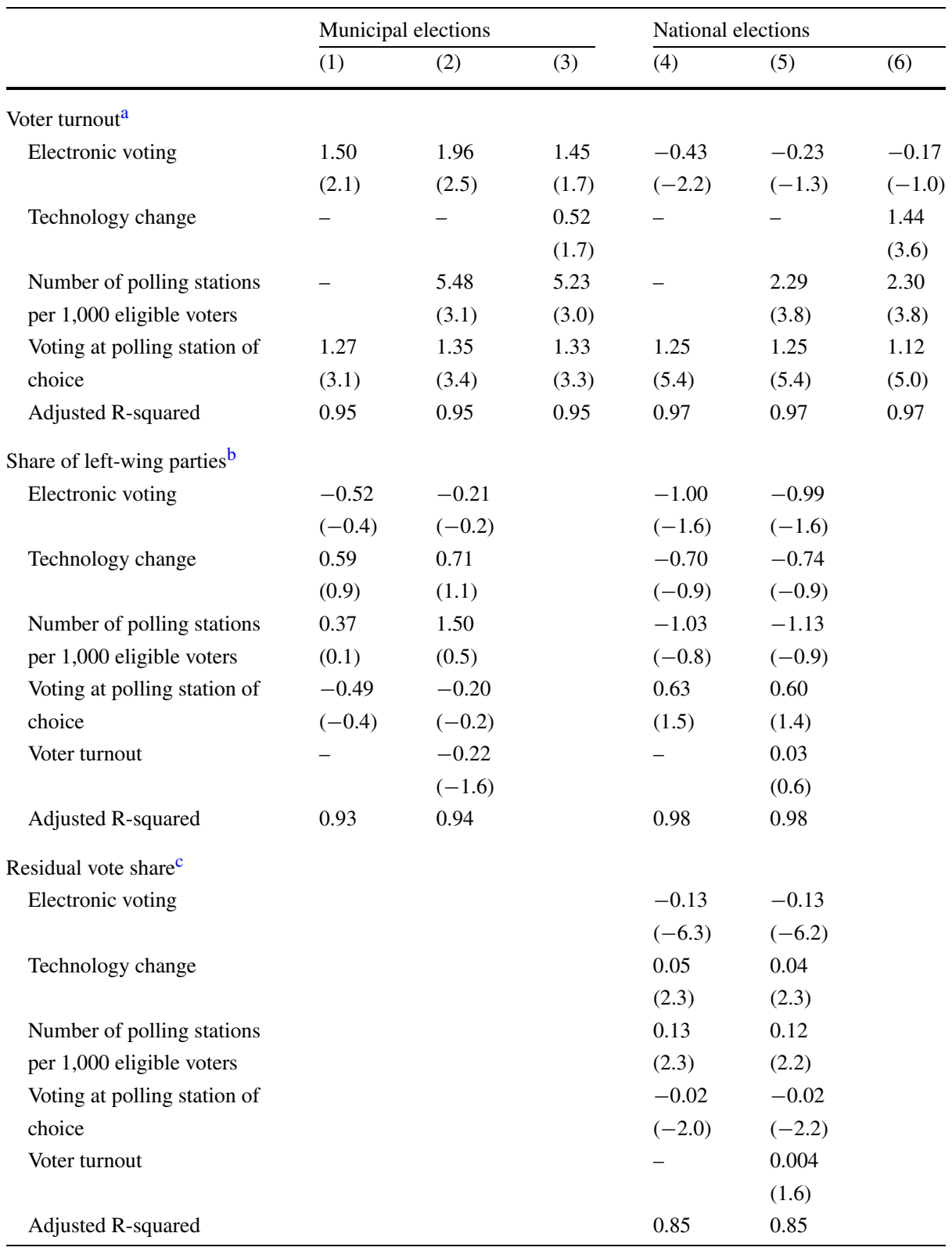

Fixed-effect panel weighted least squares estimation, using the number of eligible voters in 1998 as weights; $t$-values in parentheses, based on robust standard errors clustered by municipality. All estimations include municipal fixed effects, year dummies, and other controls (see text)

a Dependent variable: voter turnout, defined as all votes cast, whether counted or not, as a percentage of the number of eligible voters

${ }^{\mathrm{b}}$ Dependent variable: percentage share of votes cast for left wing parties (SP, GL, PvdA and D66)

${ }^{\mathrm{c}}$ Dependent variable: percentage share of residual votes in total votes cast 
voting equipment coefficient, and turnout has no significant effect on the share of residual votes. Interestingly, both polling station density and changes in voting technology increase the share of residual votes, but these effects are not large.

Our data allow testing for a possible asymmetry between the effect of moving from paper ballots to electronic voting and the effect of a reverse change (prior to the 2006 national election). To this end, we include a dummy for the reverse change, and test whether its coefficient is the negative of the coefficient on electronic voting. In all cases $p$-values exceeded 0.1 . Thus, we cannot reject the hypothesis that the effects are symmetric. The power of the test is limited, given the small number of reverse changes in the data. However, while the fraction of municipalities that reverted to paper ballots is $3 \%$, the change applied to $8 \%$ of the voters.

\section{Robustness check}

As a robustness check, we also analyze data on self-reported voting behavior from a survey among eligible voters. The data are from the CentERpanel, a representative sample of the Dutch population, except the institutionalized. ${ }^{10}$ For both the 2003 and the 2006 national elections, respondents were asked whether they voted and, if so, for which party. ${ }^{11}$ In the survey, the fraction of respondents reporting to have voted is higher than the actual observed turnout ( 0.93 versus 0.80 , both numbers averaged over 2003 and 2006). This is a common phenomenon, which has been noted before in other settings (see e.g., Silver et al. 1986). Social pressure is an important determinant of turnout (Gerber et al. 2008), so people may be reluctant to confess they did not vote. However, this bias is unlikely to be related to voting technology. The shares of left wing votes in both data sources are closer to each other ( 0.49 versus 0.45$)$. Of the 2,637 people participating in the panel, 1,964 answered the voting behavior questions (74\%). We were able to identify the voting technology (using zip code information) for 1,466 respondents. Of these, 40 lived in a municipality using DREs in 2003 and paper ballots in 2006, while 26 lived in a municipality using paper in 2003 and DREs in 2006. For the remaining respondents, the voting technology was the same in both elections.

Table 3 reports regression results from two linear probability models with individual specific fixed effects, for having voted and for having voted left wing. We find significant effects of the option to vote at the polling station of own choice, but no significant effects for the voting technology variable. This result is similar to that of the analysis of municipal level data. Again, we do not find evidence for an asymmetry between the effect of moving from paper ballots to electronic voting and the effect of a reverse change (not reported).

\section{Conclusion}

We find that electronic voting has had a small positive effect on voter turnout in Dutch elections, when used for the first time. The permanent effect is not statistically significant at the $95 \%$ confidence level.

\footnotetext{
${ }^{10}$ See www.centerdata.nl.

${ }^{11}$ The first question was worded as follows (translated from Dutch): "Last Wednesday, elections for parliament took place. Did you vote?" (1. Yes, I voted myself; 2. Yes, I mandated someone to vote on my behalf; 3. No). The second question was: "For which party did you vote?" (followed by a list of parties, including "blank", for the respondent to check).
} 
Table 3 Effects of voting technology on voting behavior

\begin{tabular}{lll}
\hline & Voted & Voted left wing \\
\hline Electronic voting & -0.03 & -0.01 \\
& $(-0.1)$ & $(-0.2)$ \\
Number of polling stations per 1,000 eligible voters & -0.15 & 0.02 \\
& $(-0.4)$ & $(0.1)$ \\
Voting at polling station of choice & 0.05 & 0.01 \\
& $(5.0)$ & $(2.1)$ \\
Adjusted R-squared & 0.74 & 0.89 \\
$N$ & 2,932 & 2,725 \\
\hline
\end{tabular}

Fixed-effect panel least squares estimation; $t$-values in parentheses, based on robust clustered standard errors. Both estimations include individual specific fixed effects

Electronic voting has a sizable negative impact on the number of residual votes. This is only to be expected, as errors on behalf of the voter leading to a residual vote are virtually impossible with electronic voting. When using voting machines, residual votes are likely to be intentional blank votes only. This result differs from that of Ansolabehere and Stewart (2005), who find that DREs perform comparably to paper ballots in American gubernatorial and senatorial elections, and worse than paper in presidential elections. This might be due to differences between the machines used in the Netherlands and those used in the USA, or to differences in the complexity or length of the ballots in both countries.

We do not find an effect of voting technology on the share of left wing parties, either in municipal, or in national elections. Our results therefore do not provide indications of voting irregularities related to voting equipment. Also, we do not find any evidence of an asymmetry between the effects of introducing and abandoning electronic voting.

Our results show that it is important to distinguish between the temporary effects of the introduction of new voting technology and the permanent effects of these technologies themselves. Moreover, omission of the number of polling stations (which we found to decrease upon the introduction of electronic voting) biases the coefficient reflecting the effect of electronic voting on voter turnout downward. This might help explain the discrepancy between our results and those reported by Card and Moretti (2007) with regard to the effect on voter turnout.

Finally, we find that voter turnout may be improved by allowing voters to vote at the polling station of their own choice. This reform increased turnout by about one percentage point in both municipal and national elections in the Netherlands.

To conclude, the introduction of electronic voting does not seem to have had much impact on election results in the Netherlands. Of course, this is as it should be.

Acknowledgements We thank Kees Aarts and the anonymous referees for helpful comments and Johannes van der Veer for excellent research assistance.

Open Access This article is distributed under the terms of the Creative Commons Attribution Noncommercial License which permits any noncommercial use, distribution, and reproduction in any medium, provided the original author(s) and source are credited. 


\section{References}

Ansolabehere, S., \& Stewart III, C. (2005). Residual votes attributable to technology. The Journal of Politics, 67(2), 365-389.

Bertrand, M., Duflo, E., \& Mullainathan, S. (2004). How much should we trust difference in differences estimates? Quarterly Journal of Economics, 119(1), 249-275.

Besley, T., \& Case, A. (2000). Unnatural experiments? Estimating the incidence of endogenous Policies. The Economic Journal, 110(467), F672-F694.

Brady, H. E., Buchler, J., Jarvis, M., \& McNulty, J. (2001). Counting all the votes: The performance of voting technology in the United States. Department of Political Science, University of California, Berkeley.

Card, D., \& Moretti, E. (2007). Does voting technology affect election outcomes? Touch-screen voting and the 2004 Presidential election. Review of Economics and Statistics, 89(4), 660-673.

Commission on Electronic Voting (2004). Interim report on the secrecy, accuracy and testing of the chosen electronic voting system.

Dee, T. S. (2007). Technology and voter intent: Evidence from the California recall election. Review of Economics and Statistics, 89(4), 674-683.

Gerber, A. S., Green, D. P., \& Larimer, C. W. (2008). Social pressure and voter turnout: Evidence from a large-scale field experiment. The American Political Science Review, 102(1), 33-48.

Haspel, M., \& Knotts, H.G. (2005). Location, location, location: Precinct placement and the cost of voting. The Journal of Politics, 67(2), 560-573.

Herrnson, P. S., Niemi, R. G., Hanmer, M. J., Bederson, B. B., Conrad, F. C., \& Traugott, M. W. (2008). Voting technology. The not-so-simple act of casting a ballot. Washington: Brookings Institution Press.

Herron, M. C., \& Wand, J. (2007). Assessing partisan bias in voting technology: The case of the 2004 New Hampshire recount. Electoral Studies, 26(2), 247-261.

Kimball, D. C., Owens, C. T., \& McAndrew Keeney, K. (2004). Unrecorded votes and political representation. http://www.umsl.edu/ kimballd/unrep.pdf. Accessed 17 April 2008.

Knack, S., \& Kropf, M. (2003). Voided ballots in the 1996 Presidential Election: A county-level analysis. The Journal of Politics, 65(3), 881-897.

Kurz, C., Rieger, F., \& Gonggrijp, R. (2007). Beschreibung und Auswertung der Untersuchungen an NEDAPWahlcomputern. Berlin.

Lott, J. R. (2008, in press). Non-voted ballots, the cost of voting, and race, Public Choice.

Nagel, J. H., \& McNulty, J. E. (1996). Partisan effects of voter turnout in senatorial and gubernatorial elections. The American Political Science Review, 90(4), 780-793.

Roseman, G. H., \& Stephenson, E. F. (2005). The effect of voting technology on voter turnout: Do computers scare the elderly? Public Choice, 123(1-2), 39-47.

Silver, B. D., Anderson, B. A., \& Abramson, P. R. (1986). Who overreports voting? The American Political Science Review, 80(2), 613-624.

Tomz, M., \& Van Houweling, R. P. (2003). How does voting equipment affect the racial gap in voided ballots? American Journal of Political Science, 47(1), 46-60. 